\title{
Métodos de enxertia para a produção de mudas de seringueira em viveiro suspenso
}

\author{
Grafting methods for production of rubber tree seedlings in \\ suspended nursery
}

\author{
Karla Borelli Rocha ${ }^{1}$, José Henrique Tertulino Rocha ${ }^{1}$ e Antonio Natal Gonçalves ${ }^{2}$
}

\begin{abstract}
RESUMO
A fim de desenvolver um protocolo de produção de mudas de seringueira que atenda as determinações da Resolução SAA - 24 objetivou-se avaliar a taxa de sobrevivência da enxertia em porta-enxertos produzidos em viveiro suspenso. Dentre os métodos de propagação vegetativa existentes, testou-se a enxertia por borbulhia, a enxertia por garfagem fenda cheia e a enxertia por garfagem fenda lateral em 452 porta-enxertos de seringueira. Avaliou-se o efeito do diâmetro dos porta-enxertos, diâmetro do enxerto, relação diâmetro do enxerto/diâmetro do porta enxerto, época do ano, estádio fenológico e método de enxertia na sobrevivência das mudas. Obteve-se sucesso na enxertia de mudas produzidas em viveiro suspenso, tanto o método de borbulhia quanto pelo método de garfagem fenda cheia. Ajustes quanto à temperatura e umidade da casa de vegetação e quanto ao excesso de látex na fenda de enxertia devem ser realizados para se obter maior sobrevivência na enxertia por garfagem em fenda cheia. Não se obteve sucesso com o método de garfagem em fenda lateral. Observou-se que assim como no sistema convencional, o sucesso da enxertia em mudas produzidas em viveiros suspensos apresenta grandes variações ao longo do ano, sendo o verão, a época em que obteve-se maior sucesso. É possível produzir mudas de seringueira em viveiro suspenso pelo método de enxertia por borbulhia, a pleno sol, com um ciclo de 12 meses sendo que com o diâmetro de $7,2 \mathrm{~mm}$, já é possível ter boa soltura de casca e boa sobrevivência da enxertia por borbulhia. Para a enxertia por garfagem, o maior sucesso foi obtido quando utilizou-se enxertos no estádio fenológico C.
\end{abstract}

Palavras-chave: Borbulhia; Garfagem; Hevea brasiliensis; Propagação vegetativa

\begin{abstract}
ABTRACT
In order to develop a protocol for rubber tree seedling production that conforms with the Resolution SAA-24 the objective of this study was to evaluate the survival of grafting on rootstocks produced in a suspended nursery. Among the propagation methods, we tested the budding and grafting by cleft grafting (top cleft and side slit) on 452 rubber tree rootstocks. Assessed were the effect of rootstock diameter, diameter of the graft, relationship of graft diameter / rootstock diameter, season of year, phenology stage and type of graft on survival of seedlings. Success was obtained by grafting seedlings produced in suspended nurseries with the budding method and with top cleft grafting method. However, adjustments in the greenhouse humidity and temperature and on the latex production in the cleft must be done to obtain high survival in grafting by cleft grafting. There was no success with the grafting method by side slit. It was observed that, just as in the conventional system, the success of grafting on seedlings grown in suspended nurseries varies widely throughout the year, and in summer greater success was obtained. Is feasible to produce rubber tree seedlings in suspended nursery by budding, in a production cycle of 12 months, since with $7.2 \mathrm{~mm}$ diameter the bark can be easily removed and the bud fixed with high rates of success. For vegetative propagation by grafting the highest success was obtained when we used scions at the phenology stage C.
\end{abstract}

Keywords: Budding; Grafting; Hevea brasiliensis; Vegetative propagation

\section{INTRODUÇÃO}

A seringueira [Hevea brasiliensis (Willd. ex Adr. de Jussieu) Muell. Arg.] pertencente à família Euphorbiaceae é considerada a espécie de maior valor econômico dentro do gênero, por produzir borracha natural e por ser a única espécie plantada comercialmente (GONÇALVES et al., 1989).

1. Departamento de Engenharia Florestal, Faculdade de Agronomia e Engenharia Florestal - FAEF. Garça / SP, Brasil. E-mail: karlaborelli0@gmail.com

2. Escola Superior de Agricultura "Luiz de Queiroz" - ESALQ, Universidade de São Paulo, USP. Piracicaba / SP, Brasil.

Sci. For., Piracicaba, v. 46, n. 120, p. 646-656, dez. 2018 DOI: dx.doi.org/10.18671/scifor.v46n120.13 
Além de despertar interesse econômico, gera benefícios sociais e ambientais (MENDES et al., 2012). Em 2016, a área plantada com seringueira no Brasil totalizou 229.964 ha (IBÁ, 2017), a produção e o consumo de borracha natural, foram de 185 mil toneladas e 413 mil toneladas, respectivamente (IRSG, 2015). Burger e Smith (2007) projetaram para 2020 demanda mundial de borracha 2,5 milhões de toneladas superior à produção.

Com as perspectivas de aumentar a área plantada de seringueira no Brasil, torna-se necessário ampliar a capacidade de produção de mudas (OLIVEIRA, 2006). Atualmente, as mudas de seringueira são formadas principalmente, por meio da enxertia por borbulhia em porta-enxertos oriundos de sementes (CARDINAL; GONÇALVES; MARTINS, 2007). Comumente, os porta-enxertos são produzidos em canteiros, diretamente no solo, ou em sacos de polietileno preenchidos com solo. Com aproximadamente $2,5 \mathrm{~cm}$ de diâmetro a $5 \mathrm{~cm}$ do solo, a parte aérea do porta-enxerto é substituída por propágulo de clones mais produtivos. Estas mudas ficam aptas ao plantio definitivo em um período que pode chegar a 24 meses (PEREIRA, 1986).

Além do longo período de produção, este sistema pode ocasionar a disseminação de pragas e doenças, prejudicando a formação dos seringais. Mudas produzidas desta forma também apresentam baixa sobrevivência no campo, aumentando os custos de implantação e podendo levar a perdas de produtividade dos seringais (PEREIRA et al., 2007). Diversas alternativas estão sendo discutidas para garantir a qualidade das mudas, dentre elas a produção de porta-enxertos em viveiros suspensos. Nesse sistema, os porta-enxertos são formados em recipientes plásticos contendo substrato vegetal e mantidos em bancadas suspensas, assegurando que as raízes das mudas não tenham contato direto com o solo (SÃO PAULO, 2015).

Diversos estudos foram conduzidos a respeito da produção de porta-enxertos em viveiros suspensos (BARRETO et al., 2016; GUIDUCCI, 2014; MUNIZ, 2016; NOBILE; PARO; FARINELLI, 2017). Entretanto, trabalhos englobando todo o ciclo de produção de mudas enxertadas de seringueira em viveiros suspensos são escassos.

Como o grande desafio da produção de mudas de seringueira é a sobrevivência do enxerto, objetivou-se testar três métodos de propagação vegetativa: enxertia por borbulha, por garfagem fenda cheia e garfagem fenda lateral, na produção de mudas em viveiro suspenso.

\section{MATERIAL E MÉTODOS}

O experimento foi conduzido no viveiro do Departamento de Ciências Florestais da ESALQ/ USP em Piracicaba, São Paulo $\left(22^{\circ} 42^{\prime} 30^{\prime \prime} \mathrm{S}\right.$ e $47^{\circ} 38^{\prime} 30^{\prime \prime} \mathrm{W}$ e altitude de $\left.546 \mathrm{~m}\right)$. O clima da região, de acordo com a classificação de Köppen é do tipo Cwa, ou seja, com duas estações bem definidas, inverno frio e seco e verão quente e úmido. A precipitação anual é de $1230 \mathrm{~mm}$ e temperatura média de $21,6{ }^{\circ} \mathrm{C}$.

\section{Produção dos porta-enxertos}

Utilizou-se porta-enxertos provenientes de sementes coletadas em pomar do clone GT1. O clone GT1 foi selecionada na ilha de Java na Indonésia e é bastante difundido no Brasil, devido sua considerável produtividade. Em trabalhos realizados no Brasil foi observado que porta-enxertos produzidos com provenientes desse clone resultam nos maiores desempenhos dos enxertos (CARDINAL; GONÇALVES; MARTINS, 2007; MARTINS et al., 2000).

Os porta-enxertos foram produzidos em sacos plásticos $(15 \times 35 \mathrm{~cm})$ preenchidos com casca de pinus compostada e vermiculita, conforme a legislação vigente (BRASIL, 2009). Foi realizada semeadura direta nos sacos plásticos, utilizando de 2 a 4 sementes por recipiente, em maio de 2014. Oito meses após a semeadura os porta-enxertos foram transferidos para pleno sol, em bancada suspensa com ocupação de 45 mudas por metro quadrado.

A irrigação foi realizada por meio de um sistema automático de aspersão (modelo Mankad), com lâmina d' água de $6 \mathrm{~mm} \mathrm{dia}^{-1}$. Durante os três primeiros meses após a transferência para pleno sol, adubações diárias foram realizadas, utilizando $70 \mathrm{~mL} \mathrm{muda}^{-1}$ da solução nutritiva descrita na tabela 1 .

No desenvolvimento inicial dos porta-enxertos foi constatado o ataque de pragas e doenças. Foi necessário realizar o controle manual do mandarová (Erinnys ello L.), por meio da catação manual de ovos e lagartas e foi identificado o ataque da antracnose (Colletotrichum gloeosporioides Penz.), sendo realizado o controle químico, com a aplicação de fungicida $\left(10 \mathrm{~mL} \mathrm{~L}^{-1}\right)$ à base de clorotalonil e tiofanato-metílico, a cada 20 dias. O controle de plantas daninhas foi realizado manualmente. 
Rocha et al. - Métodos de enxertia para a produção de mudas de seringueira

em viveiro suspenso

Tabela 1 - Concentração de nutrientes na solução utilizada para a fertirrigação dos porta-enxertos e das mudas seringueira após a enxertia.

Table 1 - Nutrients concentration of the solution used to fertigation of the rootstocks and the rubber tree seedlings after grafting.

\begin{tabular}{cc}
\hline Nutrientes ${ }^{(1)}$ & Dose $\left.\mathbf{m g ~ L}^{-1}\right)$ \\
\hline $\mathrm{N}$ & 100 \\
$\mathrm{P}$ & 6 \\
$\mathrm{~K}$ & 37 \\
$\mathrm{Ca}$ & 40 \\
$\mathrm{Mg}$ & 9 \\
$\mathrm{~S}$ & 8 \\
$\mathrm{~B}$ & 0,14 \\
$\mathrm{Cu}$ & 0,04 \\
$\mathrm{Fe}$ & 0,30 \\
$\mathrm{Mn}$ & 0,39 \\
$\mathrm{Zn}$ & 0,09 \\
$\mathrm{CE}\left(\mathrm{mS} \mathrm{cm}{ }^{-1}\right)$ & $\mathbf{1 , 5}$ \\
\hline
\end{tabular}

(1) Os fertilizantes utilizados para o preparo da solução nutritiva, fontes de N; Ca; K; P; S; Mg; Cu; Fe; Mn; Zn e B, respectivamente foram uréia, nitrato de cálcio, nitrato de potássio, fosfato monoamônico (MAP), sulfato de magnésio, sulfato de cobre, sulfato de ferro, sulfato de manganês, sulfato de zinco e ácido bórico.

\section{Procedimentos das enxertias}

Antes das enxertias, os diâmetros dos porta-enxertos foram medidos a 5 e a $10 \mathrm{~cm}$ de altura a nível do substrato com paquímetro digital. De posse dessas informações, foram estipulados seis classes diamétricas para realização das enxertias (Tabela 2). De janeiro a abril de 2015 dois enxertadores realizaram as enxertias utilizando três métodos de propagação de plantas, sendo eles: enxertia por borbulhia, enxertia por garfagem fenda cheia e enxertia por garfagem fenda lateral.

Tabela 2 - Quantidade de plantas enxertadas por método de enxertia em função das classes diamétricas Table 2 - Number of seedlings grafted by method in different diameter class.

\begin{tabular}{|c|c|c|c|c|}
\hline \multirow{2}{*}{ Classes diamétricas } & \multicolumn{3}{|c|}{ Métodos de enxertia } & \multirow{2}{*}{ Total } \\
\hline & Garfagem em fenda cheia & Garfagem em fenda lateral & Borbulhia & \\
\hline$<5,6 \mathrm{~mm}$ & $20^{1}$ & 0 & 0 & 20 \\
\hline $5,6-7,1 \mathrm{~mm}$ & 51 & 20 & 0 & 71 \\
\hline $7,2-8,7 \mathrm{~mm}$ & 48 & 13 & 39 & 100 \\
\hline $8,8-10,3 \mathrm{~mm}$ & 10 & 3 & 101 & 114 \\
\hline $10,4-11,9 \mathrm{~mm}$ & 0 & 0 & 58 & 58 \\
\hline$>11,9 \mathrm{~mm}$ & 1 & 0 & 87 & 88 \\
\hline Total & 130 & 36 & 285 & 451 \\
\hline
\end{tabular}

'Número de plantas enxertadas pelos diferentes métodos propostos.

Foram selecionados porta-enxertos que apresentavam perfeitas condições sanitárias e em plena atividade vegetativa. As hastes contendo os propágulos foram coletadas em um minijardim clonal hidropônico de seringueira (clone RRIM 600 sobre GT1) produzido em uma casa de vegetação no mesmo departamento. Para as enxertias por garfagem fenda cheia e fenda lateral foram utilizadas brotações nos estádios fenológicos A, B1, B2 e C (HALLÉ; OLDEMAN; TOMLINSON, 1978). Após a coleta, as brotações foram mantidas em baldes plásticos e no decorrer das enxertias, água foi borrifada sobre as hastes, para garantir maior conservação. O canivete utilizado pelos enxertadores foi desinfetado em álcool comercial nos intervalos de cada enxertia.

As mudas foram enxertadas pelos seguintes métodos:

Enxertia por borbulhia - Foi realizada em porta-enxertos que apresentavam diâmetro superior a 7,2 mm. A incisão foi efetuada a $5 \mathrm{~cm}$ de altura do substrato, com posterior retirada da casca, encaixe da borbulha e amarração com fita plástica transparente em espiral de baixo para cima. As mudas enxertadas foram mantidas a pleno sol. Semanalmente, foi verificada a sobrevivência do enxerto, mas somente aos 21 dias após a enxertia, a fita transparente foi retirada. Aos 30 dias, a parte aérea foi podada, com corte em bisel a $13 \mathrm{~cm}$ de altura acima do nível do substrato (Figura 1). 


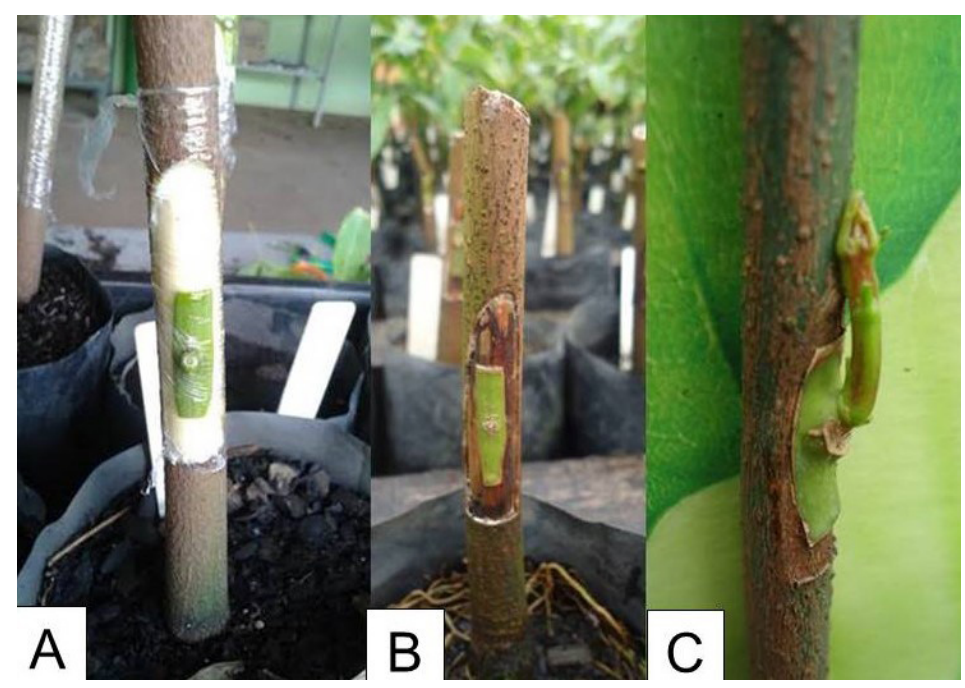

Figura 1 - Enxertia por borbulhia de seringueira em porta-enxertos produzidos em viveiro suspenso. (A) Detalhe da abertura da janela, fixação da borbulha e amarração com fita transparente; (B) Retirada da fita após constatação da sobrevivência do enxerto e poda da parte aérea; (C) Desenvolvimento da gema.

Figure 1 - Budding of rubber tree in suspended nursery. (A) Details of window opening and bud fixation; (B) Budding survival and tape removal; (C) Bud development.

Após a poda da parte aérea, as adubações via rega foram retomadas utilizando as mesmas concentrações (Tabela 1) com aplicações quinzenais de $200 \mathrm{~mL}$ por muda. A adubação foi realizada ao final da tarde, após a última irrigação.

Enxertia por garfagem em fenda cheia - Procedeu-se a enxertia por meio da retirada da parte aérea do porta-enxerto, a $10 \mathrm{~cm}$ de altura acima do nível do substrato, posterior a abertura de fenda central de $2,5 \mathrm{~cm}$. Nos enxertos das brotações clonais foram realizados corte duplo-bisel (corte em "V") e após tal procedimento, o enxerto foi inserido no porta-enxerto e amarrado com a fita plástica transparente (Figura 2).

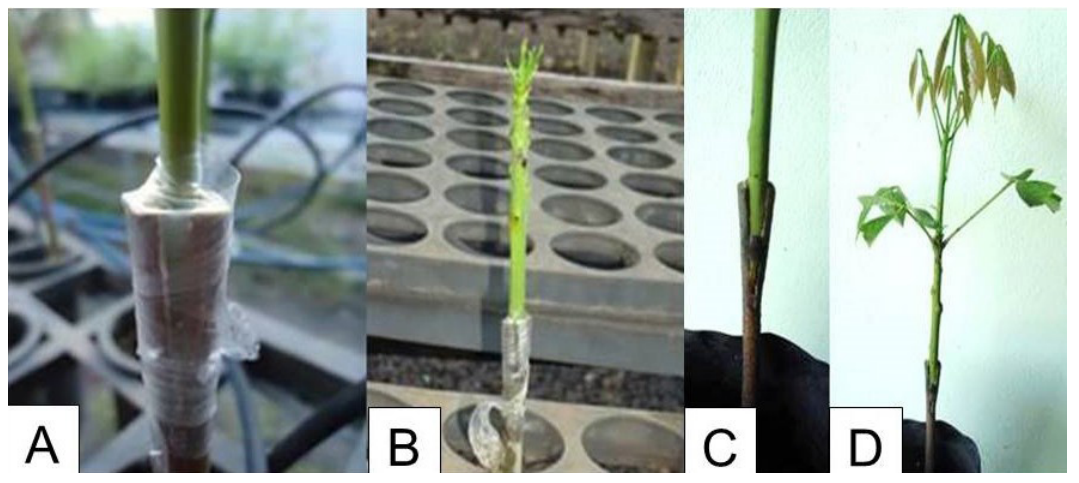

Figura 2 - Enxertia por garfagem em fenda cheia em porta-enxertos de seringueira. (A) Detalhe do corte e amarração com fita transparente; (B) Início da brotação do enxerto; (C) Retirada da fita transparente; (D) expansão da área foliar 30 dias após a enxertia.

Figure 2 - Cleft grafting in rubber tree in suspended nursery. (A) Cleft details; (B) beginning of the graft growth; (C) tape removal and grafting healing; (D) Leaf area expansion 30 days after grafting.

Após a enxertia, as mudas foram mantidas em casa de vegetação, modelo em arco, com cobertura plástica leitosa. O ambiente foi mantido úmido por meio de nebulização (modelo de emissão: Green Mist), com lâmina d' água de $11 \mathrm{~mm} \mathrm{dia}^{-1}$. Durante o período experimental, a temperatura média máxima foi de $43,6{ }^{\circ} \mathrm{C}$ com média mínima de $12,8{ }^{\circ} \mathrm{C}$ e a umidade relativa do ar máxima esteve em torno de $88 \%$ com mínima de $51 \%$.

Trinta dias após a enxertia foi removida a fita plástica das plantas que apresentaram emissão de lançamentos foliares. Aos 45 dias após a enxertia as mudas foram transferidas para casa de sombra com tela de $50 \%$, onde permaneceram por 10 dias. O sistema de irrigação foi por microaspersão com emissão modular e lâmina d' água de $8 \mathrm{~mm} \mathrm{dia}^{-1}$. Posteriormente a área foliar foi reduzida a $50 \%$ e as mudas transferidas para área a pleno sol. 
Enxertia por garfagem em fenda lateral - Foi efetuada nos porta-enxertos, a abertura lateral de uma fenda de $2,5 \mathrm{~cm}, 10 \mathrm{~cm}$ acima do nível do substrato. Nos enxertos, foi feito um corte de meia cunha, utilizando-se hastes apicais com 10-15 cm de comprimento. Paro o encaixe do enxerto no porta-enxerto e colocação da fita transparente (Figura 3), foram adotados os mesmos procedimentos utilizados por Moraes et al. (2013) em Eucalyptus sp.. O manejo após a enxertia foi o mesmo das mudas enxertadas por garfagem em fenda cheia.

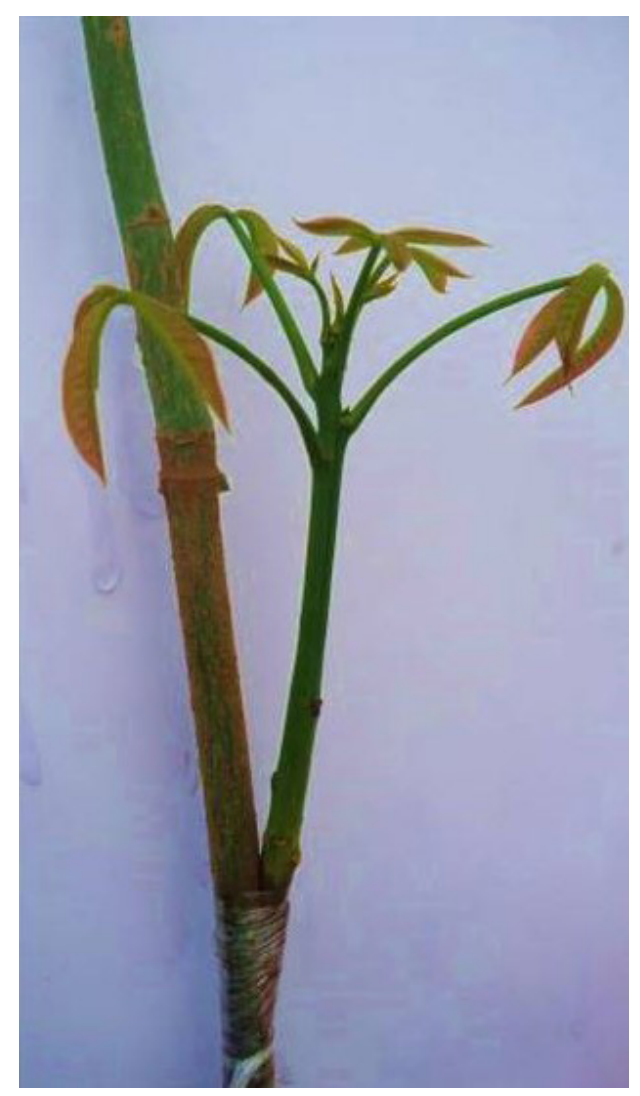

Figura 3 - Enxertia por garfagem em fenda lateral em porta-enxertos de seringueira.

Figure 3 - Grafting method by side slit in rubber tree in suspended nursery.

\section{Avaliações}

Os diâmetros dos porta-enxertos foram medidos antes das enxertias, com auxílio de um paquímetro digital, na altura de $5 \mathrm{~cm}$ (divisão das classes diamétricas) e a $10 \mathrm{~cm}$ (altura onde foi realizado o corte para enxertia por garfagem) acima do nível do substrato. Além da medida do diâmetro do porta-enxerto, foram realizadas medidas do diâmetro do enxerto, logo após as enxertias por garfagem.

A enxertia por borbulhia foi considerada como bem sucedida quando as borbulhas apresentavam-se verdes, túrgidas e fixas na haste dos porta-enxertos. Para a enxertia por garfagem, considerou-se que enxertos vivos aqueles seriam aqueles que se mantinham verdes, obtendo-se a porcentagem de sobrevivência da enxertia. Foram realizadas avaliações semanais para verificação da sobrevivência das enxertias.

No final do experimento observou-se por meio de fotografias microscópicas, a regeneração dos tecidos na região da enxertia por garfagem fenda cheia. Foram removidas cinco seções transversais em plantas com 60 e 90 dias após as enxertias. As seções foram retiradas em regiões próximas à enxertia com uma serra e os acabamentos foram executados com micrótomo de deslize. Os registros fotográficos foram realizados sem escala por meio do microscópio Zeiss com lente Epiphan-Neofluar 2,5x/0,06 HD 422320-9960.

As diferenças entre os métodos de enxertia, diâmetro do enxerto e do porta-enxerto e estádios fenológicos foram verificadas pelo teste exato de Fisher. Utilizou-se o programa estatístico Statistical Analysis System (SAS 9.3) for Windows para realização das análises. 


\section{RESULTADOS E DISCUSSÃO}

\section{Efeito do método e época da enxertia}

A enxertia por borbulhia apresentou sobrevivência de $45 \%$, sendo a maior $(\mathrm{p}<0,001)$ entre os métodos testados. Durante os meses de janeiro e fevereiro, a sobrevivência foi aproximadamente $60 \%$, caindo para próximo de $50 \%$ no mês de março, e em abril, foi inferior a 30\%, por esse motivo optou-se por cessar a técnica (Tabela 3). Esse fato ressalta a influência da época do ano na sobrevivência do enxerto. De acordo com Simão (1971), a viabilidade dos métodos de enxertia está relacionada, na maioria das vezes, à espécie, idade do porta-enxerto e época do ano de realização da enxertia. Pelo método tradicional, a enxertia é realizada apenas nos meses quentes e úmidos, visto que nos meses frios e secos não é possível remover a casca do porta-enxerto. Mendes (1959) observou redução da taxa de sobrevivência da enxertia para patamares inferiores a 30\% a partir de meados do mês de março. Martins et al. (2017) em recente cartilha técnica sobre enxertia de seringueira recomenda que esta seja realizada apenas no verão. Observações e comunicações pessoais indicam que no inverno, quando a planta entra em dormência, não ocorre a soltura da casca dos porta-enxertos, impedindo o sucesso da enxertia. Uma vez que se força a remoção da casca, o câmbio é ferido, não ocorrendo o pegamento da borbulha.

Tabela 3 - Número de mudas enxertadas (NE) em cada um dos dias de enxertia, nos diferentes métodos e seus respectivos percentuais de sobrevivência (PS)

Table 3 - Number of seedlings grafted (NE) by grafting method in each day and its respective survival percentage (PS).

\begin{tabular}{|c|c|c|c|c|c|c|}
\hline \multirow{3}{*}{$\begin{array}{l}\text { Data da } \\
\text { enxertia }\end{array}$} & \multirow{2}{*}{\multicolumn{2}{|c|}{ Borbulhia }} & \multicolumn{4}{|c|}{ Garfagem } \\
\hline & & & \multicolumn{2}{|c|}{ Fenda Cheia } & \multicolumn{2}{|c|}{ Fenda Lateral } \\
\hline & NE & PS & NE & PS & NE & PS \\
\hline $25-01-15$ & 37 & 59 & 33 & 52 & 11 & 0 \\
\hline $01-02-15$ & 79 & 59 & 24 & 17 & 11 & 0 \\
\hline $08-02-15$ & 36 & 64 & 30 & 7 & 14 & 0 \\
\hline 08-03-15 & 10 & 50 & 15 & 20 & - & - \\
\hline $31-03-15$ & 14 & 21 & 4 & 0 & - & - \\
\hline $18-04-15$ & 36 & 33 & 11 & 45 & - & - \\
\hline $21-04-15$ & 16 & 19 & 2 & 0 & - & - \\
\hline $30-04-15$ & 57 & 21 & 11 & 18 & - & - \\
\hline Total & 285 & 45 & 130 & 25 & 36 & 0 \\
\hline
\end{tabular}

Para a enxertia por borbulhia, a maior sobrevivência, 55\%, foi observada em porta-enxertos com diâmetro variando de 7,2 a 10,3 mm (Tabela 4). Esse fato pode estar associado ao uso de borbulhas produzidas em minijardim clonal e, também à utilização de hastes recém-coletadas. Apesar de inesperado, esse fato é extremamente vantajoso, pois com o uso de borbulhas mais novas é possível enxertar mudas com diâmetro inferior a $10 \mathrm{~mm}$. Isso resultaria em redução no ciclo de produção das mudas de seringueira quando produzidas em viveiro suspenso.

Tabela 4 - Número de mudas enxertadas (NE) em função da classe diamétrica nos diferentes métodos e seus respectivos percentuais de sobrevivência (PS)

Table 4 - Number of seedlings grafted (NE) by grafting method in each diameter class and its respective survival percentage (PS).

\begin{tabular}{|c|c|c|c|c|c|c|}
\hline \multirow{3}{*}{$\begin{array}{c}\text { Classes } \\
\text { diamétricas }\end{array}$} & \multicolumn{6}{|c|}{ Métodos de enxertia } \\
\hline & \multicolumn{2}{|c|}{ Borbulhia } & \multicolumn{2}{|c|}{ Garfagem fenda cheia } & \multicolumn{2}{|c|}{ Garfagem fenda lateral } \\
\hline & NE & PS & $\mathrm{NE}$ & PS & NE & PS \\
\hline$<5,6 \mathrm{~mm}$ & 0 & 0 & 20 & 25 & 0 & 0 \\
\hline $5,6-7,1 \mathrm{~mm}$ & 0 & 0 & 51 & 20 & 20 & 0 \\
\hline $7,2-8,7 \mathrm{~mm}$ & 39 & 56 & 48 & 27 & 13 & 0 \\
\hline $8,8-10,3 \mathrm{~mm}$ & 101 & 55 & 10 & 50 & 3 & 0 \\
\hline $10,4-11,9 \mathrm{~mm}$ & 58 & 34 & 0 & 0 & 0 & 0 \\
\hline$>11,9 \mathrm{~mm}$ & 87 & 33 & 1 & 0 & 0 & 0 \\
\hline Total & 285 & 45 & 130 & 25 & 36 & 0 \\
\hline
\end{tabular}


Os porta-enxertos com diâmetro superior a 10,3 $\mathrm{mm}$ apresentaram baixa sobrevivência da borbulhia (34\%). Esse comportamento não era esperado, visto que, de acordo com os padrões estabelecidos de produção e comercialização de mudas de seringueira no Brasil, o diâmetro do porta-enxerto recomendado deve ser igual ou superior a $10 \mathrm{~mm}$ a $5 \mathrm{~cm}$ de altura acima do nível do substrato (BRASIL, 2009).

Considerando apenas os porta-enxertos com diâmetro entre 7,2 e 10,3 mm, enxertados no verão, foi observada sobrevivência superior a 70\%, sendo maior ou igual aos percentuais de sobrevivência encontrados no sistema convencional de produção de mudas obtidos em outros trabalhos (CARDOSO, 1961; KALIL FILHO; OLIVEIRA, 1983; LINS; CASTRO, 1979; MENDES, 1959).

Não foi obtido sucesso na enxertia por garfagem em fenda lateral. Uma semana após a enxertia, observaram-se sinais visíveis de deterioração, com escurecimento das hastes. Devido a esse fato, optou-se por enxertar com esse método apenas nos três primeiros dias (Tabela 3). As 36 mudas enxertadas não sobreviveram, sendo que este método se mostrou inviável para a produção de mudas de seringueira nas condições desta pesquisa.

As mudas enxertadas por garfagem em fenda cheia foram consideradas vivas, quando sobreviveram 30 dias após a enxertia (DAE). Após esse período a taxa de sobrevivência se estabilizou. A sobrevivência média foi de 25\% (Tabela 3). As maiores sobrevivências, 52\%, foram obtidas em janeiro. Importantes fatores como: ocorrência de doenças, demanda de água (LEMOS FILHO, 1991), tempo de cicatrização da zona enxertada, formação do calo e de novos tecidos de condução, podem ser influenciados pelas diferentes épocas do ano na enxertia por garfagem (MEDRADO et al., 1992). Segundo esses autores esse fato pode ser resultado do mau posicionamento dos tecidos ou do acúmulo de látex decorrente do corte, impedindo o contato direto entre o enxerto e o porta-enxerto.

Observou-se que as mudas enxertadas por garfagem apresentaram início de cicatrização aos $10 \mathrm{DAE}$ e expansão de área foliar aos 30 DAE (Figura 2). Em algumas plantas observou-se após 40 DAE um ligeiro aumento no diâmetro na região enxertada. Para Kester et al. (2001), esse aumento pode estar relacionado a formação do calo resultante do processo de cicatrização normal, formado por células parenquimáticas. Segundo Nunes et al. (2005), a proliferação das células é a primeira indicação do início do crescimento do enxerto, pois evidencia o restabelecimento das conexões vasculares entre os tecidos. Na figura 4, é possível visualizar a evolução dos processos de cicatrização com o início da formação de calo, em pequenos pontos da superfície de contato entre o enxerto e o porta-enxerto. Nessa parcial união já ocorre transferência de água e nutrientes entre as partes enxertadas, iniciando o mecanismo de pega (DIAS et al., 2009). Sendo assim, quanto maior a superfície de contato do parênquima entre as duas diferentes partes, maior sucesso na enxertia (SHIMOYA; GOMIDE; FONTES, 1968).

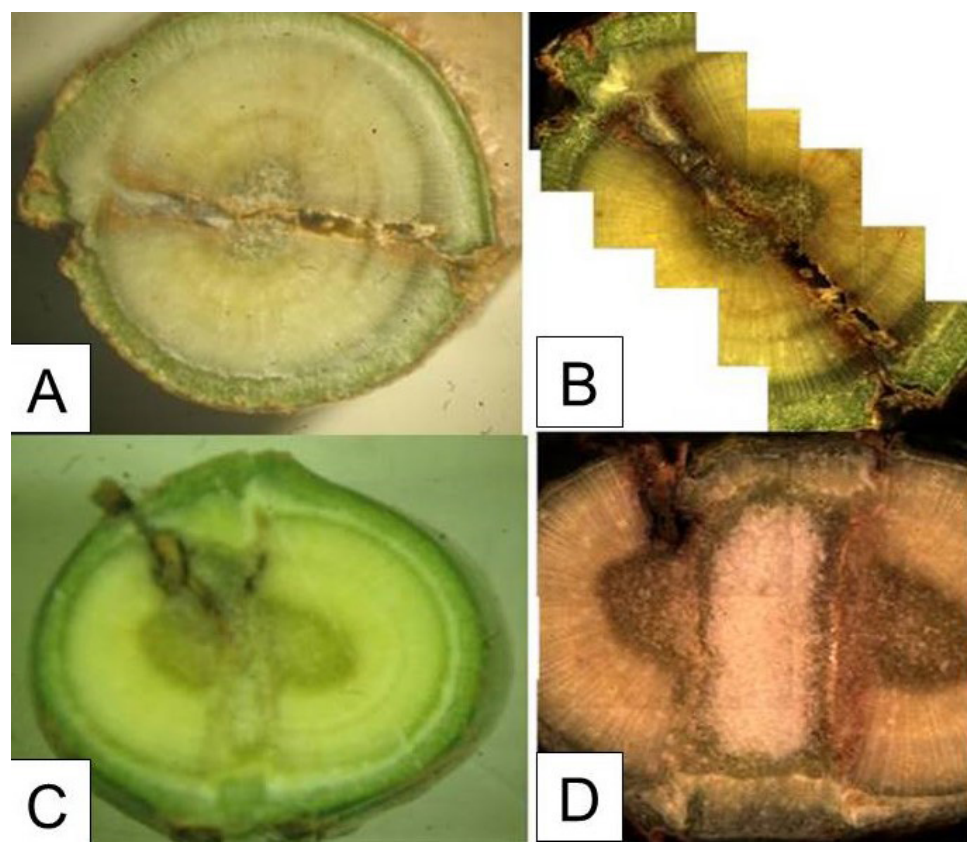

Figura 4- Seções transversais de caules de seringueira enxertados, aos 60 (A e B) e 90 dias (C e D) após a enxertia por garfagem em fenda cheia.

Figure 4- Transverse sections of grafted rubber tree stalks at 60 ( $A$ and $B$ ) and 90 days ( $C$ and $D$ ) after grafting by cleft grafting. 
Mesmo apresentando formação parcial do calo, diferenças podem existir em função da época de realização da enxertia (MEDRADO et al., 1992). Observações realizadas nesse experimento indicam que para ocorrer perfeita cicatrização são necessários mais de 90 dias de enxertia.

\section{Efeito da relação dos diâmetros do enxerto e porta-enxerto na enxertia por garfagem}

Com relação à sobrevivência das mudas enxertadas pelo método de garfagem em função dos diâmetros, pode-se verificar que a maior sobrevivência ocorreu quando o diâmetro do enxerto e do porta-enxerto estiveram entre 3,2 a $6 \mathrm{~mm}$ e entre 6 a $8 \mathrm{~mm}$, respectivamente (Figura 5). Isso significa, que o diâmetro do porta-enxerto deve ser o mesmo ou no máximo 1,5 vezes maior que o diâmetro do enxerto para se obter maior sucesso na enxertia. Este método mostrou-se inviável com enxertos que apresentavam diâmetro superior a $6,2 \mathrm{~mm}$.

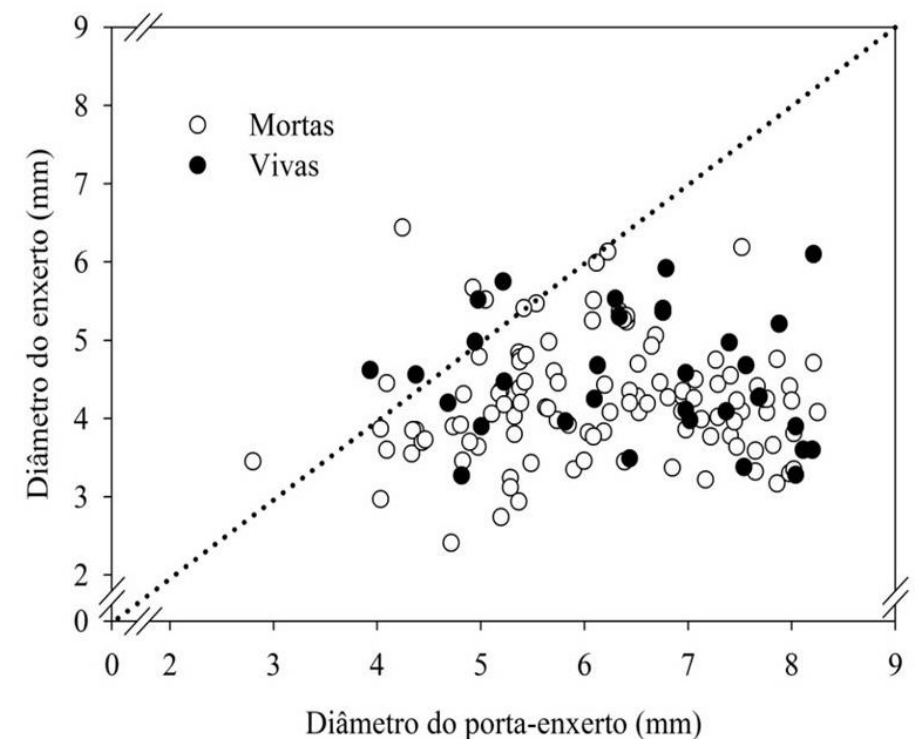

Figura 5 - Relação entre o diâmetro do enxerto e do porta-enxerto na região da enxertia sobre a sobrevivência das plantas.

Figure 5 - Relationship between graft and rootstock diameters in the grafting zone and grafting survival.

Segundo Medrado et al. (1992), as diferenças entre os tamanhos do enxerto com o porta-enxerto podem influenciar a tolerância a elevadas temperaturas e a perda de água de garfos de seringueira, e consequentemente a sobrevivência do enxerto. A seção mostrada na figura 4D apresenta relação enxerto e porta-enxerto igual a 1, apresentando aos 90 DAE uma junção das partes com cicatrização quase perfeita. Verifica-se, que a cicatrização ocorre quando há maior contato entre os câmbios das plantas. Segundo Hoffmann et al. (1996), entre o enxerto e o porta-enxerto, pode ocorrer incompatibilidade e esse fator pode influenciar a sobrevivência do enxerto. Duas plantas podem ser consideradas incompatíveis quando não há uma união perfeita (DIAS et al., 2009). Entre os principais sintomas de incompatibilidade estão: falta de união do enxerto com o porta-enxerto, diferenças entre os diâmetros, amarelecimento e desfolha do enxerto, pouco crescimento vegetativo e diferenças na consistência dos tecidos (HOFFMANN et al., 1996).

Para que o diâmetro do enxerto e do porta-enxerto coincidam, é necessário que haja uma sincronia na produção. Em trabalhos de micro-garfagem recomenda-se que a poda do jardim clonal seja realizada no dia do semeio ou no máximo 15 dias após a semeadura do porta-enxerto (MEDRADO et al., 1922). Com a produção de enxertos de seringueira em minijardim clonal, conforme proposto por Borelli (2016), melhores resultados nesse tipo de enxertia podem ser alcançados, devido à maior compatibilidade enxerto/ porta-enxerto.

\section{Efeito do estádio fenológico na enxertia por garfagem}

A maior sobrevivência da enxertia por garfagem em fenda cheia $(p=0,014)$, foi encontrada quando se utilizou enxertos do estádio fenológico C (Tabela 5). Semelhante às observações realizadas por Lemos Filho (1991), horas após as enxertias, as brotações no estádio A e B1 apresentaram perda 
Rocha et al. - Métodos de enxertia para a produção de mudas de seringueira

em viveiro suspenso

Tabela 5 - Número de mudas enxertadas (NE) e percentual de sobrevivência (PS) pelos métodos de garfagem em função do estádio fenológico

Table 5 - Number of seedlings grafted (NE) by grafting method in each gaft phenological stage and its respective survival percentage (PS).

\begin{tabular}{cccccc}
\hline \multirow{2}{*}{ Estádio fenológico } & \multicolumn{2}{c}{ Garfagem fenda cheia } & & \multicolumn{2}{c}{ Garfagem fenda lateral } \\
\cline { 2 - 3 } \cline { 5 - 6 } & NE & PS & 1 & NE & PS \\
\hline A & 3 & 3 & 5 & 13 & 0 \\
B1 & 32 & 24 & 14 & 0 & 0 \\
B2 & 37 & 33 & 4 & 0 \\
C & 58 & $\mathbf{3 6}$ & & 0 \\
Total & 130 &
\end{tabular}

de turgescência, resultando em mortalidade superior a 80\%. Os enxertos no estádio fenológico C, apresentaram folhas bem formadas, que consequentemente controlaram melhor as perdas de água. Além disso, segundo Medrado et al. (1992), enxertos em estádios fenológicos mais avançados e retirados de folíolos bem desenvolvidos são menos suscetíveis ao ataque de doenças e mais tolerantes às condições adversas de temperatura nos meses mais quentes do ano.

\section{CONCLUSÕES}

É possível produzir mudas de seringueira em viveiro suspenso pelo método de enxertia por borbulhia, a pleno sol, com um ciclo de 12 meses sendo que com o diâmetro de 7,2 mm, já é possível ter boa soltura de casca e boa sobrevivência da enxertia por borbulhia.

A enxertia por garfagem em fenda cheia pode ser realizada em viveiro suspenso, porém ajustes quanto à temperatura e umidade da casa de vegetação e quanto ao excesso de látex na fenda de enxertia devem ser realizados para se obter maior sobrevivência.

\section{AGRADECIMENTOS}

A primeira autora agradece a Fundação de Amparo à Pesquisa do Estado de São Paulo (FAPESP), processo $n^{\circ}$ 2013/12220-5 pela bolsa de mestrado concedida.

\section{REFERÊNCIAS BIBLIOGRÁFICAS}

BRASIL, MAPA: Ministério da Agricultura, Pecuária e Abastecimento. Instrução Normativa no 29 , 05 de agosto de 2009. Dispõe sobre as normas para a produção de sementes e de mudas de seringueira (Hevea spp.). Disponível em: < http://sistemasweb.agricultura.gov.br/sislegis/action/detalhaAto.do? method=consult arLegislacaoFederal >. Acesso em: 18 Ago. 2017.

BARRETO, R. F;; MARUYAMA, W. I.; BARDIVIESSO, D. M.; RODRIGUES, T. S.; SERAGUZI, E. F.; BARBOSA, A. V. Adubação de porta-enxertos de seringueira em viveiro suspenso. Floresta, Curitiba, v. 46, n. 1, p. 1-9, 2016.

BORELLI, K. Produção de mudas de seringueira em viveiro suspenso. 2016.87 p. Dissertação (Mestrado em Ciências) -Escola Superior de Agricultura "Luiz de Queiroz", Universidade de São Paulo, Piracicaba, São Paulo.

BURGER, K.; SMITH, H. P. The natural rubber market review, analysis, polices and outlook. Cambridge: Woodhead Publishing: 2007. 137 p.

CARDINAL, A. B. B.; GONÇALVES, P. D.; MARTINS, A. L. M. Influência de seis porta-enxertos sobre a produção de clones superiores de seringueira. Bragantia, Campinas, v. 66, n. 2, p. 277-284, 2007

CARDOSO, M. Conservação de hastes de seringueira destinadas a enxertia. Bragantia, Campinas, v. 20, n. 13, p. 513-516, 1961.

DIAS, F. P; CASTRO, D. M; MENDES, A. N. G.; VALLONE, H. S.; CARVALHO, A. M.; CARVALHO, G. R. Estudo anatômico de cafeeiros enxertados. Ciência e Agrotecnologia, Lavras, v. 33, n. 3, p. 735-742, 2009.

GONÇALVES, P. S.; CARDOSO, M.; BOAVENTURA, M. A. M.; MARTINS, A. L. M.; LAVORENTTI, C. Biologia, citogenética e ploidia de espécies do gênero Hevea. O Agronômico, Campinas, v. 41, n.1, p.40-64, 1989. 
GUIDUCCI, E. P. Sistemas de produção de porta-enxertos de seringueira. 2014. 48 p. (Mestrado em Agronomia) - Faculdade de Ciências Agrárias, Universidade Estadual Paulista "Júlio de Mesquita Filho", Jaboticabal, São Paulo.

HALLÉ, F.; OLDEMAN, R.A.; TOMLINSON, P.B. Tropical trees and forest. Berlin: Springer, 1978. 441 p.

HOFFMANN, A.; CHALFUN, N.N.J.; ANTUNES, L.E.C.; RAMOS, J.D.; PASQUAL, M.; SILVA, C.R. R. Propagação de plantas frutíferas. Lavras: UFLA, 1996. 319 p.

IBÁ - INDÚSTRIA BRASILEIRA DAS ÁRVORES. Relatório anual 2016. São Paulo: IBA, 2017. Disponível em: < http://www.iba.org/images/shared/iba_2017.pdf >. Acesso em: 28 ago. 2017.

IRSG - INTERNATIONAL RUBBER STUDY GROUP. Production and consumption of natural rubber: rubber industry report. 2017. Disponível em: < http://www.rubberstudy.com/documents/WebSiteData_Aug2017. pdf >. Acesso em: 22 ago. 2017.

LEMOS FILHO, J. P. Aspectos fisiológicos e biometerológicos relacionados com a técnica de minienxertia da seringueira (Hevea spp.). 1991. 126 p. (Doutorado em Ciências). Instituto de Ciências Biológicas, Universidade Estatual de Campinas, Campinas, São Paulo.

LINS, A. C. R.; CASTRO, F. A. Influência do Ferbam e do anelamento da haste clonal na enxertia da seringueira (Hevea spp.), na microregião Alto Purus - AC. Rio Branco: Embrapa 1979. 12 p. (Comunicado Técnico)

KALIL FILHO, A. N; OLIVEIRA, R. P. Propagação vegetativa de clones de seringueira na região de Altamira, PA. Altamira: Embrapa, 1983. 6 p. (Comunicado Técnico, 8).

KESTER, D. E.; DAVIES JÚNIOR, F. T.; HARTMANN, H. T.; GENEVE, R. L. Hartmann and Kester's plant propagation: principles and practices. New Jersey: Prentice Hall, 2001. 880p.

MARTINS, A.L.M.; LUCA, C.A.; GONÇALVES, E.C.P.; BRITO, P.F. Produção de mudas de seringueira em bancada e substrato. CATI, 2017. 52 p.

MARTINS, A.L.M.; RAMOS, N.P.; GONÇALVES, P.S.; VAL, K.S. Influência do porta-enxerto no crescimento de clones de seringueira no estado de São Paulo. Pesquisa Agropecuária Brasileira, Brasília, v.35, n.9, p.17431750, 2000

MENDES, L. O. T. Considerações sobre a enxertia da seringueira. Boletim Técnico do Instituto Agronômico do Estado de São Paulo, Bragantia, Campinas, v. 18, n. 11, p. 141-159, 1959.

MENDES, A. D. R.; OLIVEIRA, L. E. M.; NASCIMENTO, M. N.; REIS, K. L.; BONOME, L. T. S. Concentração e redistribuição de nutrientes minerais nos diferentes estádios foliares de seringueira. Acta Amazonica, Manaus, v. 42, n. 2, p. 525 - 532, 2012.

MEDRADO, M. J. S.; LEMOS FILHO, J. P.; PEREIRA, J. P.; COSTA, J. D.; KITAZAWA, I. H.; BERNARDES, M. S.; FERNANDES, A. L. T.; POMPERMAYER, S. A. Perspectivas da micro-garfagem em seringueira. In: MEDRADO, M. J .S.; BERNARDES, M. S.; COSTA, J. D.; MARTINS, A. N. (Ed.). Formação de mudas e plantio de seringueira. Piracicaba: ESALQ- Departamento de Agricultura, 1992. p.158.

MORAES, C. B. D.; SILVA, P H. M.; ABÍLIO, F. M.; PIERONI, G. B.; GONÇALVES, A. N.; MORI, E.S. Sobrevivência de enxertos de Eucalyptus com metodologia adaptada. Circular Técnica IPEF, Piracicaba, v. 17, n. 206, p. 0117, 2013.

MUNIZ, N. P. Produções de porta-enxerto de mudas de seringueira (Hevea brasiliensis) em diferentes tipos de substratos. 2016, 26 p. Monografia (Graduação em Agronomia) - Centro Universitário da Fundação Educacional de Barretos, Barretos, SP.

NOBILE, F.O.; PARO, G.F; FARINELLI, R. Soluções nutritivas para produção de porta-enxertos de seringueira. Revista Florestal Brasileira. Colombo, v. 37, n. 89, p. 73-80, 2017.

NUNES, J. C. O.; ABREU, M. F.; DANTAS, A. C. M.; PEREIRA, A. J.; PEDROTTI, E. L. Caracterização morfológica de microenxertia em macieira. Revista Brasileira de Fruticultura, Jaboticabal, v. 27, n. 1, p. 80-83, 2005.

Sci. For., Piracicaba, v. 46, n. 120, p. 646-656, dez. 2018 DOI: dx.doi.org/10.18671/scifor.v46n120.13 
OLIVEIRA, J. P. Crescimento e nutrição mineral de porta-enxertos de seringueira (Hevea spp.) em função da idade. 2006. 77 p. (Mestrado em Solos e nutrição de plantas) - Universidade Federal Rural da Amazônia, Bélem, 2006.

PEREIRA, J. P. Formação de mudas de seringueira. In: SIMPÓSIO SOBRE A CULTURA DA SERINGUEIRA NO ESTADO DE SÃO PAULO.1986. Piracicaba, SP Anais... Campinas: Fundação Cargill, 1986, p. 139-164.

PEREIRA, A. V.; ZAMUNÉR FILHO, A. N.; SILVA, R. S. ; ANTONINI, J. C. A.; VACURCA, H.; PEREIRA, E. B. C. Produção de mudas de seringueira em viveiro suspenso. In: CONGRESSO BRASILEIRO DE HEVEICULTURA, 2007, Guarapari. Anais... Guarapari, ES, 2007.

SÃO PAULO (Estado). Resolução SAA - 23, de 26 de junho de 2015. Estabelece exigências para cadastramento de viveiros, jardins clonais, plantas matrizes produtoras de sementes e normas técnicas de defesa sanitária vegetal, para a produção, comércio e o transporte de mudas, borbulhas e sementes de seringueira (Hevea spp.) no estado de São Paulo. Disponível em: < https://www.defesa.agricultura.sp.gov.br/legislacoes/resolucao-saa23-de-26-06-2015,1035.html > Acesso em: 28 agosto de 2017.

SHIMOYA, C.; GOMIDE, C. J.; FONTES, J. M. Estudo anatômico da enxertia em Citrus spp. Revista Ceres, Viçosa, v. 15, n. 84, p. 95-105, 1968.

SIMÃO, S. Manual de fruticultura. 7.ed. São Paulo: Agronômica Ceres, 1971. 530p.

Recebido em: 28/08/2017

Aceito: 25/05/2018 